\title{
Acts of learning worth learning from
}

\author{
KAREN VAUGHAN
}

\section{KEY POINTS}

- Learning opportunities connected to authentic practice are particularly fruitful for developing capability.

- The most profound learning involves a shift in "being" and identity, not just knowledge and skill.

- Teachers are crucial for modelling what it is to practise something in the real world. 
This article supports teachers to think about their students' acts of learning, as well as their own as teachers. It draws on research about young adults' most profound learning during their apprenticeships, cadetships, and vocational immersion programmes. The experiences of GP registrars, carpentry apprentices, and engineering technician cadets, and the perspectives of their workplace teachers and mentors, provide insights about how people can move through a kind of portal to a new level of understanding and capability. These insights can be used by teachers working with the key competencies and developing rich learning opportunities for students.

\section{Introduction}

Teachers are in the business of helping others learn, while also engaging in ongoing learning themselves. So sometimes it is necessary to take a step back to think deeply about the most profound acts of learning. What are those acts? How do they happen? This article supports teachers to think about students' acts of learning, as well as their own. It shares research about young adults engaged in profound acts of learning as part of their everyday work while engaged in apprenticeships, cadetships, and vocational immersion programmes. The learner-practitioners' experiences, and teacher and mentor perspectives, presented in the article suggest some interesting reflective challenges for teachers in schools. How can these experiences help your work? First, they relate to how you help students develop "the capabilities for living and lifelong learning" described in The New Zealand Curriculum (Ministry of Education, 2007) (NZC). Secondly, they relate to how you are as a learner, and a mentor to other teachers, in your teaching career.

The New Zealand Council for Educational Research (NZCER) recently completed a research project, Knowing Practice, which studied apprenticeship in general practice (GP) medicine; carpentry; and engineering technician work (Vaughan, Bonne, \& Eyre 2015). The project's focus was on learners who are no longer school students, and who work in contexts that are very different from classroom and/or school-based ones. However the project is relevant to teachers in schools because the findings are about experiences of learning and capability development. By looking at the learning needed later in life, we can think about how schools might prepare students for that. This article is particularly relevant for teachers with a keen interest in dispositional development.

There is also a strand of particular relevance to careers advisors and pathways educators. Knowing Practice was deliberately designed to take account of John Dewey's sense of "vocation": a life direction comprising each individual's motivations and interests and continued occupational practice in areas that are valued and shaped by society (Dewey, 1916). This is very different from today's conventional ideas that "vocational" means "hands-on" learning and that "vocational pathways" are for non-academic or disengaged students. Going back to Dewey's original meaning allowed Knowing Practice to include three very different fields (GP medicine, carpentry, and engineering) spanning different parts of the tertiary education sector and New Zealand Qualifications Framework. GP registrars, carpentry apprentices, and engineering technician cadets were therefore all involved in vocational education in the sense of connecting their interests with ongoing capability development in a particular occupation. This has implications for how students at schools are prepared to think about their future learning and work.

We can also use Knowing Practice findings to help us think about teachers' own learning as adults. The GP registrars, carpentry apprentices, and engineering technician cadets saw themselves as lifelong learners. Their teachers and mentors understood that supporting learner-practitioners to build fieldspecific capability rested in large part with teachers' and mentors' own lifelong-learning dispositions. So the education occurring in Knowing Practice is as relevant to teachers in their own work-their vocation-as it is to the learners they teach. 


\section{The research}

The Knowing Practice project studied the development of vocational capability through apprenticeship. Forty-one GP registrars, carpentry apprentices, and engineering technician cadets ("learner-practitioners") took part, along with their respective workplace teachers and mentors. Researchers observed a business-as-usual teaching or mentoring session and then interviewed the learner-practitioner and the teacher or mentor.

Interviews explored perspectives on the learning arrangements, and learner-practitioners' most significant learning experiences related to being a GP, carpenter, or engineering technician (for the mentor/teacher, it was an experience they believed would lead to significant learning for a learner-practitioner). Researchers reinterviewed learner-practitioners approximately 10 months later, probing again for significant learning experiences, as well as perspectives on the characteristics of recognisably good or not-so-good practitioners in their field. The main report (Vaughan et al., 2015) proves more detail about the approach and methods.

\section{What it looks like when learners cross vocational thresholds}

In interviews, we asked learner-practitioners to describe their most significant learning experiences. ${ }^{1}$ Their accounts were, of course, specific to their own field of practice. However, there were remarkably similar highlevel themes. Their most significant learning experiences revealed to them an integrated "big picture" of practice, connecting theory to practice. The experiences were personally and professionally challenging, sometimes involving painful lessons or counterintuitive realisations. There was no going back once reaching these "new ways of seeing".

We developed the idea of "vocational thresholds" to understand these experiences and their role in capability development. When learner-practitioners crossed a vocational threshold, they reached a new level of understanding of their work and their role. The threshold crossing marked the development of greater capability. The vocational threshold idea is built on the threshold concepts idea (Meyer \& Land, 2003), which has been used by tertiary educators to identify disciplinary concepts that act as a gateway to students' understanding. Threshold concepts are characteristically transformative in perception and perspective; often irreversible and unlikely to be forgotten; integrative of different and previously hidden aspects; sometimes bounded conceptually; and possibly troublesome in relation to previous beliefs (Meyer \& Land, 2003).
Vocational thresholds are similar to threshold concepts but distinguished from them in two important ways. First, vocational thresholds arise out of authentic, everyday practice, not a classroom or lecture theatre. Secondly, they lead to a transformation that is not just about knowledge and skills but about how to be. This makes a vocational threshold like a portal to new capability and part of a series of encounters while in ongoing practice. It seems likely that vocational thresholds can be encountered by practitioners in any field, including teaching.

\section{GP registrars facing uncertainty}

General practitioners (GPs) are doctors with a clinical speciality in primary health care. The hallmarks of general practice are that it is accessible, continuing, comprehensive, and in the context of whānau, family and community. The Royal New Zealand College of General Practitioners' (RNZCGP) General Practice Education Programme (GPEP) offers qualified doctors a 3-year fulltime equivalent "vocational immersion" training path to become vocationally registered in the specialty of general practice.

GP registrars experienced a sharp surge in the level of uncertainty in their work as they moved from a hospital context (a pre-requisite to their GP training) to a community context. Registrars now had individual responsibility for patients and their continuity of care-both over time and between other healthcare professionals. They had no direct access to hospitallevel diagnostic testing and only 15-30 minutes for a consultation with a patient on whom treatment plans could not be imposed. Registrars felt both excited and daunted by trying to cross this vocational threshold. They now had the responsibility of "being it" in a more negotiated, relationship-centred model of healthcare.

GP registrars contended with an ethic of care centred on relationships, not just clinical knowledge. They often found they might "just" be listening to patients or "being there" for them. For registrars who enjoyed the technical, problem-solving challenges of medicine, this was disturbing, prompting some to feel like they were "not doing anything". Others found a new and rewarding dimension to medical practice in listening well and deciding with the patient what the problems were, which to pursue, and how to do so.

In hospital I learned to address a problem and give the medicine. Here, I am trying to change lifestyle. When I get positive feedback, that it has clicked, and [the patient] wants to change, that makes me a GP. In hospital we could not change anything. We could diagnose really good stuff ... But here, there's a satisfaction in looking after a man. (Kendrick, GP registrar) 
The GP ethic of care also required registrars to pay attention to caring for themselves, in order to be fully available to patients. To cross this vocational threshold, their expertise now had to derive from a very different kind of knowing — and management—about their own strengths, frailties, and anxieties, and the nature of their (ongoing) relationships with patients.

GP registrars were able to have ad hoc discussions with colleagues, especially in clinics which had an "open door" policy for consulting each other. Registrars could sometimes also observe more expert GPs by sitting in on their consultations. GP teachers particularly engaged registrars in "approximations of practice" (Grossman et al., 2009), role-playing consultations, or difficult conversations with patients. GP teachers modelled collegiality. This collegiality was not just a "giving back", or for congenial workplace relations. This helped registrars develop a disposition and way of practising that counterbalanced the tendency to become isolated and overwhelmed, which ultimately would affect patients.

[My teacher] has a good attitude about me having a go ... I appreciate the freedom he gives me. I explore the boundaries of my practice but while knowing he is extremely open to me approaching him for advice or help. (Danni, GP registrar)

\section{Carpentry apprentices learning about craft}

The Building and Construction Industry Training Organisation (BCITO) is responsible for developing and managing industry qualifications for the building and construction sector. Carpenters work with materials such as timber, concrete, and steel to construct buildings from scratch and to alter, repair, and renovate them. Becoming a qualified carpenter is a crucial first step towards becoming a fully-fledged builder in New Zealand.

Carpentry apprentices described crossing a threshold to an increasingly sophisticated interplay between their minds, their bodies, and their physical environment of tools and materials. Building became less straightforward as the complexities involved in a project revealed themselves. This steered apprentices away from the idea of there being one right method towards an increasing skilfulness in sensing the different possibilities and enacting the mind-body-environment interplay. As they were entrusted with opportunities to solve more complex problems, they began to enjoy the respect of their coworkers and clients.

As soon as you've done a good job and you look back at it and you think it's a good job, and then someone else comes along and sees it finished and you can see it in them. They say: 'That looks awesome, mate.' ... it feels amazing. (Pete, carpentry apprentice)
While technical building prowess was important to apprentices (and of course to their employers), apprentices referred in particular to the development of attitudes and values such as pride, craftsmanship, and independence. Being able to independently identify and correct mistakes was a key aspect of their learning, developing a carpenter's "eye", building "nous", and a craftsman-like character. Apprentices' experiences drew attention to the commonplace tendency in education to think about values separately from cognitive processing and technical skill. Yet carpentry apprentices' experiences in crossing vocational thresholds demonstrated that aesthetic and craft values direct choice of tool, material, and technique as well as directing behaviour and stimulating problemsolving and problem-finding (Rose 2005, p. 204).

Carpentry apprentices "chewed the fat" with their coworkers throughout the day, bonding through physical hardship, joint problem-solving, and humour. Carpentry apprentices also had reflective space with their ITO training advisors whose visits were deliberately organised as a conversation about learning and took an assessment approach that was formative, not just summative, providing "windows on episodes of practice" (Eraut \& Hirsch, 2007, p. 17).

The transition from supervised to unsupervised work was often scaffolded by the trainer (usually the employer or a senior builder), together with the ITO training advisor. This required a judgement about the apprentice's level of skill and readiness to take on more responsibility. By giving them responsibility for small jobs such as ceilings or gibbing and then gradually letting out the reins, the employer or trainer could help the apprentice to "find their feet". Employers also deliberately pushed apprentices into taking full responsibility for important parts of projects, supporting them to do "perk" jobs (paid or unpaid work for friends and relatives), and develop independence.

I'm not just being someone's boy all the time. I get to take the lead. (Ricky, carpentry apprentice)

\section{Engineering technician cadets seeing the social side}

Engineering technicians solve well-defined engineering problems using a combination of practical know-how and analytic techniques. The role is positioned to complement the work of professional engineers. Engineering technician cadetships are offered by firms associated with the Institute of Professional Engineers of New Zealand's (IPENZ) Futureintech initiative.

Engineering technician cadets described crossing a vocational threshold as being like an ability to shift their focus. Much of their work involved intense devotion 
to detail-physical measurement, symbolic notation, computer-aided plan drafting, and precise calculation. Cadets were charged with ensuring accuracy of those details, to which they were deliberately restricted as learners, so they would not be overwhelmed. However, this meant they sometimes struggled to appreciate the place of their work within a project and team.

Their significant learning experiences made visible what their measurements and drawings, a small aspect of a project, enabled for the rest of the team and for the project overall. Experiences interacting with other members of the team, or people in mentoring roles, helped cadets lift their gaze, reinforce diligence, and understand their contribution as fundamental rather than trivial. They were not just taking soil samples or using a theodolite. They were engineering solutions, making things possible.

The definition of what was possible was not simply a technical one. As part of the design process they were faced with considering how people would engage with the results of their (and their team's) labour, including that the work could be contested by different groups or had differential impacts in the world. Cadets found themselves crossing over a threshold when they saw that engineering was not just a physical-technical enterprise; it was social one.

Engineering technician cadets had regular meetings with a mentor that allowed them to step back from project details and discuss an engineering mindset. Cadets also had reflective space in team debriefings about approaches that had not worked and could be improved. Discussions with peers in weekly classes provided by the Institutes of Technology and Polytechnics might also have spurred some reflective opportunities. Engineering mentors and team leaders played complementary roles in support of cadets. Mentors focused on career development and engineer world-view issues. Team leaders focused on technical development. Mentors and team leaders liaised to rotate cadets through different teams so they could gain experience in different areas of engineering. They also tried to align some of cadets' work tasks and with cadets' tertiary institution-based, part-time studies. The overall purpose of these alignments was to help cadets develop capability, sometimes by deliberately pushing cadets' limits.

Sometimes it's good to get chucked in the deep end because it pushes you and you realise that you can do the task. That happened to me with [a specific] job. It was overwhelming-I think it was [lack of] confidence. I hadn't used the design software that much and the deadlines were tight and they were always questioning and it makes you doubt yourself ... It showed me that I can do anything if I put my mind to it and ask for help or try and figure things out myself. (Brendan, Engineering technician cadet)

\section{What the idea of vocational thresholds could mean for you when teaching students}

\section{Teachers can model what it means to really practise something}

The workplace teachers and mentors described above worked at the boundary of theory and practice, drawing directly from their own experiences and those of learnerpractitioners. GP teachers described "turning theory into people" and encouraging registrars to focus on the case before them, letting any additional clinical knowledge cohere around that. Builders (employers of carpentry apprentices) and ITO training advisors made sure that everyday work onsite and with other contractors drove the learning and assessment so that independent judgement was developed. Engineering team leaders and mentors prioritised the development of an engineering mindset through working together, and reflecting on, real projects and client relationships.

Workplace teachers, advisors, and mentors were important, not because they simply transmitted knowledge and skills, but because they acted as coconstructors of competence (Hodge, 2010). Each field has its own equivalent of a curriculum and a set of specified and assessable knowledge and skills for the occupation. However, the teachers and mentors repositioned that curriculum content so that it went beyond acquisition. By working alongside learner-practitioners, teachers and mentors showed them that knowledge was not just what was contained in textbooks but what was embodied in the practitioners themselves, who represented the vitality and evolution of practice (Wenger-Trayner \& WengerTrayner 2015). In other words, learner-practitioners had a powerful illustration of how to bring their selves to the practice. This fosters an attitude to learning that is very appropriate to capability development in any field.

\section{Dispositional development at work is linked to the key competencies}

The idea of vocational thresholds highlights the way that particular dispositions are crucial for capability development. This is similar to the vital role played by key competencies in $N Z C$. Teachers working with the key competencies can take students beyond simply learning about something. They can move students into developing knowledge, attitudes, values, and skills while engaged in doing something, and while deliberately putting attention on the process of learning.

Engagement in everyday work, with deliberate learning, allowed registrars, apprentices, and cadets to 
cultivate the attitudes and values that made knowledge and skills most useful and meaningful. GPs did not just learn about patient relationships; they had to establish and maintain them. They had to develop the disposition to want to do so, understanding that relationships lie at the heart of general practice work. Carpenters did not just read about staircases; they needed to interpret general staircase references on plans and actually build them. And they had to be disposed towards taking pride in crafting their staircases well. Engineering technicians' work was not solely in the symbolic realm such as when making traffic-flow calculations. The work also involved understanding where those calculations fitted within the work of the wider team. This work required them to be disposed towards an awareness of public safety on the roads.

The idea of vocational thresholds also highlights the importance of being immersed in practice for learning. Although theory is generally thought of as more rigorous for learning purposes, it was everyday work that made any prior or concurrent theory meaningful. Of course, having an experience is not enough on its own to trigger the crossing of a vocational threshold. Bringing together practice and theory is where teachers play a key role in helping others recognise, and cross, vocational thresholds.

Taking a cue from the dispositional emphasis in vocational thresholds, we could think about the role of dispositions in the key competencies of $N Z C$. The dispositional dimensions of learning in GP medicine, carpentry, and engineering resonate strongly with the work of other education researchers who argue that learners need to engage with real-world complexity and learning that really matters (Hipkins, Bolstad, Boyd, \& McDowall, 2014; Perkins 2009). What creative, rich environments do you create for students to develop for themselves the capabilities they need to flourish both at school and beyond school, into work and further learning? Has this already heralded-or could it yet herald - the building of different relationships within your school, and between your school and community? I invite you to think about how the kinds of rich learning opportunities needed for crossing vocational thresholds might change your school.

\section{Implications for you in your teaching vocation}

How do the experiences of learning in described in this article compare to the ones you have had in your teacher learning? You might like to think about the vocational thresholds you have crossed in your career. For some teachers, it may have been about coming to the realisation that a teacher does not need to be all-knowing, or eradicate uncertainty for students. Others may have crossed a vocational threshold to become more responsive to students, developing a wider range of ways to recognise and meet different needs, by no longer working with "the class" as simple receivers of messages from an expert in front of them.

You might also like to think about what support you have provided, or could provide, to newly inducted or early career teachers. What about your long-standing colleagues? What kind of "community of practice" (Lave \& Wenger, 1991) is your school, and in what ways are people committed to learning together through collegial relationships? How do you model what it is to be a teacher beyond knowledge of curriculum content and a high level of pedagogical skill? Who once did this, or now does, for you?

This article has focused on tertiary-level learning, but its findings are highly relevant to what teachers and students do in school. The Knowing Practice project's broad, Deweyan view of vocation can help get past the persistent contrast made in society between "hands-on" learning for students who are disengaged, and academic, higher-order learning for others. What could be more hands-on than being a GP touching their patients? What could be more higher-order than bringing together mathematical calculation with aesthetic considerations as a carpenter?

Knowing Practice also draws our attention to the way that the most profound learning-crossing vocational thresholds - involves development of disposition and identity. It highlights a role for teachers that goes beyond transmitting knowledge to modelling real-world practice. We could play with the idea of "community of practice" (Lave \& Wenger, 1991). It is not uncommon to talk about, or aspire towards, teachers being members of a community of practice. But isn't the school as much a place of work for the students? As a workplace, the culture of the school could be considered a "dispositional mileux" (Carr et al., 2010), with opportunities and conditions for teacher and student learning, including dispositional development. To end, I'd like to pose a further question that is perhaps quite radical: how could your school be a community or landscape of practice-for teachers and students?

\section{Acknowledgements}

NZCER's Knowing Practice project was supported by the Building and Construction Industry Training Organisation (BCITO), the Royal New Zealand College of General Practitioners (RNZCGP), and the Institute of Professional Engineers of New Zealand (IPENZ). It was funded through NZCER's Government Grant and 


\section{TEACHERS AS COMMUNITIES OF LEARNING PROFESSIONALS}

Ako Aotearoa's National Project Fund. Thanks also go to Rose Hipkins for her advice on this article, and to my Knowing Practice colleagues, Linda Bonne and Jan Eyre.

\section{Note}

I This interview question was adapted from a similar one in Grossman et al's (2009) study about tertiary education courses and experiences prior to entering careers in clinical psychology, the clergy, and teaching.

\section{References}

Carr, M., Smith, A.B., Duncan, J., Jones, C., Lee, W., \& Marshall, K. (2010). Learning in the making. Disposition and design in early childhood. Rotterdam, Netherlands: Sense Publishers.

Dewey, J. (1916). Democracy and education. An introduction to the philosophy of education. Los Angeles, CA: Indo-European Publishing.

Eraut, M., \& Hirsch, W. (2007). The significance of workplace learning for individuals, groups and organisations. Oxford, UK: ESRC Centre on Skills, Knowledge and Organisational Performance (SKOPE).

Grossman, P., Compton, C., Igra, D., Ronfeldt, M., Shahan, E., \& Williamson, P.W. (2009). Teaching practice: A crossprofessional perspective. Teachers College Record, 111(9), $2055-2100$.

Hipkins, R., Bolstad, R., Boyd, S., \& McDowall, S. (2014). Key competencies for the future. Wellington: NZCER Press.

Hodge, S. (2010). Trainers and transformation: Facilitating the "dark side" of vocational learning. International Journal of Training Research, 8, 53-62. http://dx.doi.org/10.5172/ ijtr.8.1.53
Lave, J., \& Wenger, E. (1991). Situated learning: Legitimate peripheral participation. Cambridge, MA: Cambridge University Press. http://dx.doi.org/10.1017/ CBO9780511815355

Meyer, J.H.F., \& Land, R. (2003). Threshold concepts and troublesome knowledge: Linkages to ways of thinking and practising within the disciplines. London, UK: Economic and Social Research Council.

Perkins, D. (2009). Making learning whole: How seven principles of teaching can transform education. San Francisco, CA: Jossey-Bass.

Rose, M. (2005). The mind at work: Valuing the intelligence of the American worker. New York, NY: Penguin Books.

Wenger-Trayner, E., \& Wenger-Trayner, B. (2015). Learning in a landscape of practice: A framework. In E. Wenter-Trayner, M. Fenton-O'Creevy, S. Hutchinson, C. Kubiak \& B.

Wenger-Trayner (Eds.), Learning in landscapes of practice: Boundaries, identity, and knowledgeability in practicebased learning (pp. 13-30). Oxon, UK: Routledge.

Vaughan, K., Bonne, L., \& Eyre, J. (2015). Knowing practice: Vocational thresholds for GPs, carpenters, and engineering technicians. Wellington: New Zealand Council for Educational Research and Ako Aotearoa. Retrieved from http://www.nzcer.org.nz/research-knowing-practice-pdf

Karen Vaughan is a chief researcher at the New Zealand Council for Educational Research and leads the research programmes on Learning at Work and Youth Pathways. She welcomes your thoughts about this article, especially about how the ideas in it might resonate with your school or teaching practice.

Email: karen.vaughan@nzcer.org.nz 